\title{
La novela centroamericana sobre el migrante: Las murallas y Al otro lado del San Juan'
}

\author{
(Central American Novel about \\ the Migrant: \\ Las murallas and $A$ l otro \\ lado del San Juan)
}

\section{Gustavo Camacho Guzmán² \\ Universidad Nacional, Costa Rica}

\begin{abstract}
Resumen
Se analizan dos novelas centroamericanas de un migrante como protagonista: Las murallas, de Adolfo Méndez Vides y Al otro lado del San Juan, de Petronio Marcenaro Romero (Nicaragua, 1964). En ambas se hace hincapié en el desarraigo, la marginalidad y la discriminación. En Las murallas, los personajes no superan sus condiciones precarias de vida; en Al otro lado del San Juan, se muestra un espacio en que prevalecen la xenofobia y la opresión del migrante, en el marco de una inminente guerra entre Costa Rica y Nicaragua.
\end{abstract}

1 Recibido: 3 de junio de 2019. Aceptado: 18 de noviembre de 2019. El presente trabajo fue desarrollado en el marco de la Maestría en Estudios de Cultura Centroamericana (MECC), de la Universidad Nacional, Costa Rica.

2 Escuela de Literatura y Ciencias del Lenguaje. Correo electrónico: gustavo_a_72@hotmail.com.

Letras 68 (2020), ISSN 1409-424X; eISSN 2215-4094 


\begin{abstract}
Two Central American novels with a migrant as protagonist are analyzed: Las murallas, by Adolfo Méndez Vides, and Al otro lado del San Juan, by Petronio Marcenaro Romero. Uprooting, marginalization and discrimination are emphasized in both novels. In the former, the characters are never able to leave their precarious lives, while in the latter xenophobia and the oppression of migrants prevail, within the framework of an imminent war between Costa Rica and Nicaragua.
\end{abstract}

Palabras clave: literatura centroamericana, narrativa centroamericana contemporánea, Adolfo Méndez Vides, Petronio Marcenaro Keywords: Central American literature, contemporary Central American narrative, Adolfo Méndez Vides, Petronio Marcenaro

En las corrientes destacadas en la narrativa centroamericana contemporánea, están la variedad de temas y la adopción de múltiples esquemas y programas narrativos, que se resisten a las clasificaciones y al encasillamiento de los textos en corrientes más generales. Werner Mackenbach trata algunos aspectos de tales tendencias, cuyo denominador común es la presentación de la violencia como tema de la narrativa contemporánea; como ejemplo, las novelas sobre los procesos revolucionarios centroamericanos, sobre la disidencia o la posguerra centroamericana ${ }^{3}$. Según Mackenbach, la literatura centroamericana experimentó un auge a partir de la década de 1970, así como una apertura a nuevas formas y corrientes ${ }^{4}$, entre las que se destaca la literatura de la violencia: Baile con serpientes (1996); El arma en el hombre (2001), del hondureño Horacio Castellanos

3 Para un análisis detallado de estas tres tendencias de la literatura centroamericana contemporánea, véase Héctor Leyva, «La novela de la revolución centroamericana (1960-1990)» (Tesis de grado. Universidad Complutense de Madrid, 1995). Un cuestionamiento a la noción de literatura de posguerra se encuentra en Margarita Rojas, «Literatura en guerra: la narrativa contemporánea en Centroamérica», Letras 49, 2011: 27-50.

4 Werner Mackenbach, «Entre política, historia y ficción. Tendencias en la narrativa centroamericana a finales del siglo Xx», Istmo 36 (2018). Disponible en: $<$ http://istmo.denison.edu/n15/articulos/mackenbach.html>. 
Moya; o Managua salsa city (2000), del nicaragüense Franz Galich. También se destaca la novela histórica: Asalto al paraíso (1992), de la chileno-costarricense Tatiana Lobo; El burdel de las Pedrarias (1995), del panameño-nicaragüense Ricardo Pasos Marciacq; El misterio de San Andrés (1996), del guatemalteco Dante Liano, así como la novela sobre la situación del migrante 5 .

Respecto de esta última tendencia, tres novelas de la región que tratan el tema son Big Banana (2000), del hondureño Roberto Quesada; y, las analizadas en el presente estudio, Las murallas (1997), del guatemalteco Adolfo Méndez Vides; y Al otro lado del San Juan (2007), del nicaragüense-costarricense Petronio Marcenaro ${ }^{6}$. El migrante adopta algunos rasgos principalmente como un ser desarraigado o huérfano, que lucha por sobrevivir en un ambiente hostil o indiferente a la condición del migrante ${ }^{7}$. Resalta el que ellas, la descripción del migrante cuenta con rasgos particulares, que permiten visualizar ciertas características en común: el desarraigo, la marginalidad, la discriminación y la hostilidad de un medio que prometía mejores condiciones de vida. Llama la atención el que Al otro lado del San Juan (2007) muestra un rasgo ausente en las otras dos novelas: la presencia de acontecimientos situados en un futuro con respecto al momento de la escritura. En tal futuro, hay una amenaza de guerra inminente entre Costa Rica y Nicaragua por una antigua disputa: los derechos de navegación por el río San Juan, cuyo cauce marca su frontera entre ellos.

5 Otras tendencias en la literatura centroamericana son la novela sobre la ciudad: Fritongo Morongo (2007), la novela de carácter político: Vuelo de cuervos (1997), la novela homoerótica: Paisaje con tumbas pintadas en rosa (1999), la novela negra: El laberinto del verdugo (2010), Verano rojo (2010), y aun más reciente, la novela que trata temas del esoterismo y el ocultismo: Espectros de Nueva York (2015).

6 Roberto Quesada, Big Banana (Barcelona: Seix-Barral, 1999); Adolfo Méndez Vides, Las murallas (México: Alfaguara, 1997); y Petronio Marcenaro, Al otro lado del San Juan (San José: Editorial Costa Rica, 2007).

7 Un caso ligeramente diferente es el de la novela Big Banana. En ella, el protagonista (hondureño) viaja a Estados Unidos para convertirse en actor y acaba siendo amigo de Steven Spielberg, quien le ofrece un papel de importancia en la película que él dirige. Véase Roberto Quesada, Big Banana (Barcelona: Seix-Barral, 1999). 


\section{De la Antigua a Nueva York: Las murallas}

En su análisis sobre esta novela de Méndez Vides, Margarita Rojas $^{8}$ indica que en ella está la imagen de un doble; entre Ramiro y su compañero (el narrador) se efectúa una suplantación de personalidad: el narrador logra conseguir un trabajo, mantiene a Ramiro y envía dinero y fotografías a la familia de este como si fuera Ramiro. La relación entre ambos personajes llega a convertirse en una suerte de matrimonio, en el que Ramiro reprocha a su amigo que vaya de fiesta y llegue tarde; incluso, puede compararse con una relación filial ${ }^{9}$.

Tal relación entre los personajes invierte las identidades: en Nueva York, el personaje que logra establecerse es el narrador, mientras que para quienes reciben noticias de ellos en la Antigua (Guatemala), ciudad de donde proceden los personajes, es Ramiro quien cuenta con estabilidad económica ${ }^{10}$. Por ello, para Rojas el texto presenta «una identidad doble: falsa en el ambiente real - Nueva York- y falsa también en el ambiente de la ausencia —en Antigua-. Así, ante los ausentes, el hombre asume las vestiduras del amigo; ante los presentes, lo oculta» $\rangle^{11}$. Asimismo, la autora anota una serie de oposiciones en el aspecto temporal y espacial del texto: la Antigua, otrora metrópolis de Centroamérica, remite al lugar de origen de los personajes, al interior, a la memoria y al pretérito, mientras que Nueva York se refiere al exterior y al futuro ${ }^{12}$.

Los personajes que migran se caracterizan por su sentimiento de desarraigo cuando se trata de su lugar de origen. Ramiro abandona

8 Margarita Rojas, «Máscaras y peregrinajes en una ciudad anónima. Las murallas, de Méndez Vides», La ciudad y la noche. La nueva narrativa latinoamericana (San José: Farben, 2006) 1930.

9 Rojas, 21-22. Incluso, para Rojas, la relación entre ambos toma rasgos propios de una relación de madre enferma que recibe los cuidados de su hijo, sobre todo al final de la novela, cuando el narrador cuida de Ramiro una vez que este ha quedado ciego.

10 Rojas, 23.

11 Rojas, 25.

12 Rojas, 27. 
a su familia en Guatemala, sin preocuparse por la situación de sus hijos o de su esposa. Su partida implica matar una parte esencial del ser, hecho que impide, a la postre, el regreso: «cuando uno nace por ejemplo en la Antigua y mama las campanadas de la iglesia de San Francisco [...] ya no se puede apartar de aquí sin matar algo natural en uno, que es vital, como el alma misma» ${ }^{13}$. El recuerdo de la patria está marcado por la tristeza y la nostalgia, por esta razón, algunos de los compatriotas en Nueva York con quienes tratan Ramiro y el protagonista se conforman con la práctica de las tradiciones guatemaltecas; esto implica vivir en una Guatemala que solo existe en el recuerdo: esparcir pino en el suelo en momentos de fiesta, celebrar en Semana Santa una procesión «con la réplica en miniatura del $\mathrm{Na}$ zareno de la Merced», organizar posadas en Navidad y celebrar cada año el día de independencia son remedos de la patria abandonada, en los cuales los «Antigüeños Anónimos» manifestaban su tristeza hasta llegar al llanto ${ }^{14}$.

Sin embargo, el regreso es un tema tabú para el grupo, pues Fidel, a quien se considera dirigente de esta organización anónima y en cuya casa se realizan las actividades mencionadas, responde al protagonista cuando se comenta la posibilidad del retorno: «se necesita mucho valor para volver» ${ }^{15}$. El recuerdo contrasta con la realidad en la que viven: si el recuerdo remite a la tradición, la realidad lleva a los personajes a la desesperación y a una vida precaria, opuesta a las expectativas y las condiciones que esperaban encontrar cuando salieron del país natal; el protagonista expresa: «Me había convertido en otro latino más a la sombra del país anglo, viviendo ratosamente, visto por los gringos como ignorante, conato de esclavo entre estos edificios repetidos y sin pasión»» ${ }^{16}$.

13 Méndez Vides, 58.

14 Méndez Vides, 61-62.

15 Méndez Vides, 63.

16 Méndez Vides, 59. Incluso, otra característica del migrante es la capacidad de multiplicarse. Ello se encuentra al inicio del texto, cuando el narrador deambula por las calles de Nueva York y se encuentra con grupos de coreanos que expulsan paulatinamente a los neoyorkinos de algunos 
Al sentimiento de soledad, desarraigo y desesperación, se suma el carácter de la ciudad: Nueva York se describe como una ciudad amurallada. Las murallas que rodean la ciudad, tal como apunta Rojas, son los rascacielos que prohíben el paso libre de los personajes. Si la Antigua cuenta con aire puro y un espacio abierto rodeado de volcanes, Nueva York es una ciudad amurallada, en la que el personaje se encuentra encerrado, de ahí que la ciudad pueda considerarse una cárcel, no solo por los muros de concreto, sino también por la imposibilidad de volver a la tierra natal, y por ello, los personajes se refugian en la nostalgia ${ }^{17}$.

Sin embargo, la realidad que afrontan quienes salen del país natal contrasta con la concepción del migrante de quienes se quedan en el lugar de origen: se admira a quienes salieron de su país, en busca de condiciones de vida mejores, aunque esto no deja de ser un ideal, en tanto la vida del extranjero es difícil: el espacio es hostil, el migrante se halla a sujeto a su propia fortuna y a un salario precario para poder sobrevivir. Esta condición parece la única posible, en virtud de que es generalizado entre los guatemaltecos en Nueva York el desinterés por legalizarse como residentes: «No querían tener papeles formales ni nacionalizarse, porque al hacerlo sabían que serían presa fácil para parar de soldados peleando en alguna guerra que no tenía nada que ver con nosotros» ${ }^{18}$.

De este modo, al migrante no le queda más que encerrarse en sí mismo y rememorar la patria perdida, o adoptar las maneras y el modo de vida neoyorkino, aunque esta adopción no sea más que un cambio de apariencia. Ejemplo de esta segunda opción es el de Kate, colombiana que oculta sus orígenes y su apariencia de latinoamericana al no utilizar más idioma que el inglés y valerse de los tintes en el cabello y

sectores de la ciudad, tomados al fin por los coreanos; Méndez Vides, 15.

17 No es casual el que Corominas defina la etimología de este vocablo como el «deseo doloroso de regresar». Corominas, 416.

18 Méndez Vides, 90. 
de los intentos de aclarar el color de la piel para borrar todo rastro de su procedencia latinoamericana y no regresar a Colombia ${ }^{19}$.

Para este personaje, el lugar de origen es un espacio donde habita el mal; de ahí que buscar una vida en el exilio se convierte en la única opción para poder vivir. Kate dice: «[...] yo no puedo creer que quede algo bueno, por eso nos venimos todos para acá» $\rangle^{20}$. De esta manera, las razones para vivir en un país ajeno son escapar de lo que no se desea vivir y buscar en el extranjero lo que en el propio país no se puede conseguir. Sin embargo, esta segunda opción no pasa de ser un deseo, pues las condiciones del migrante en la ciudad de Nueva York no son las que estos personajes esperaban. Incluso, este personaje reprocha a los latinoamericanos que ha conocido la constante añoranza de la patria y el deseo de regresar ${ }^{21}$.

Kate establece una relación de amistad, que más adelante, se torna en amorío, con el narrador. Al principio de esta amistad, aparece un factor que también sirve como una de las barreras: la distancia personal «Y esa mañana, como que ella llegó muy triste y le hizo falta la compañía de alguien, y decidió romper las murallas que yo siempre edificaba entre los dos $\rangle^{22}$. Esta relación sentimental no pasa más allá de una noche, pues al personaje le remuerde haber abandonado a Ramiro a su suerte. Un hecho que suscita este cargo de conciencia es el parecido de Kate con Ramiro cuando él la ve de espaldas: «Es ridículo pero siendo ella una mujer hermosa, por detrás era muy parecida a Ramiro, y cuando se agachaba o hacía un esfuerzo se le veían los mismos huesos protuberantes $\rangle^{23}$. Además de ese parecido, el narrador recurre a una excusa para terminar la incipiente relación: a pesar de ser soltero y sin hijos, afirma que es casado y tiene hijos en la Antigua; más aún, la descripción de esa supuesta esposa coincide con

19 Méndez Vides, 82. El narrador afirma: «Ella sí no quería volver jamás a su tierra, ni de vacaciones a Cartagena o a la isla de San Andrés»; Méndez Vides, 112.

20 Méndez Vides, 102.

21 Méndez Vides, 109.

22 Méndez Vides, 103.

23 Méndez Vides, 113. 
la mujer de Ramiro ${ }^{24}$. Por tal razón, es posible considerar al personaje como un doble: no es el protagonista el que termina la relación con Kate; es Ramiro, a través de las palabras de su amigo, quien elimina la posibilidad de una relación duradera.

Esta va a ser, después de ese episodio, una constante en el protagonista: a toda persona que conocía le hacía saber que en la Antigua lo esperaba una mujer con sus hijos, como si fuera el propio Ramiro. De este modo, ambos personajes acaban siendo uno, pues cuando este pierde la vista, el amigo le ofrece sus ojos, y por ello, le cuenta historias para entretenerlo. Además, el protagonista llega al punto de no saber qué hacer de su vida si Ramiro llega a morir, por lo cual, ambos dependen del otro y uno de los dos moriría si falleciera el otro: «De tiempo en tiempo me entra la angustia por la edad, el trabajo y los años perdidos, y me agarra una opresión en el pecho, entonces me le quedo mirando fijo a Ramiro y se me nubla el futuro: ¿qué pasará conmigo el día que él muera?»» ${ }^{25}$.

Otro aspecto de interés es la comparación que en el texto se establece entre los dos personajes de los que trata la novela y los guatemaltecos que se exilian después de ellos. Esto permite considerar la existencia de dos generaciones de migrantes: la primera corresponde a Ramiro y al narrador; la segunda, a los guatemaltecos que arriban a Nueva York años después. Entre ambos grupos, es notoria la diferencia de fines e intereses: si Ramiro y su amigo salen de Guatemala con el utópico fin de ahorrar, conseguir dinero y volver a la Antigua, para la segunda generación de guatemaltecos exiliados, la idea del regreso carece de sentido: «No vinimos aquí para luego querer regresar a ese infierno, hay que amarrarnos con uñas y dientes para no resbalar». Ello implica una nueva idea de Guatemala: si para los dos amigos Guatemala era la ciudad de la Antigua, como espacio ameno con vestigios y ruinas de un pasado lejano y portentoso, para los que vienen después, el país es la guerra y la miseria. Por ello, el

24 Méndez Vides, 116.

25 Méndez Vides, 152.

92 
exilio en Nueva York es la única forma de salvarse de un infierno ${ }^{26}$. No sería casual que la última noticia que llega a los oídos de Ramiro por boca del protagonista es la desaparición de la ciudad natal: «Dicen que la Antigua ya no existe» ${ }^{27}$.

De esta manera, la novela de Méndez Vides presenta un migrante sumido en la desdicha y en el encierro que imponen las murallas: la ciudad, la distancia entre las personas y la ceguera del amigo son aspectos que condenan al personaje a vivir en un exilio del que no se puede regresar, y por ello, los personajes deben contentarse con el recuerdo, la nostalgia de la patria perdida; o bien olvidar por completo el pasado y adoptar el desarraigo y la única compañía del amigo ciego.

\section{Del Cocibolca a San José: Al otro lado del San Juan}

La otra novela que trata del migrante es la de Petronio Marcenaro. La obra muestra un rasgo poco común en la tradición literaria costarricense y centroamericana: la anticipación temporal: los acontecimientos suceden entre 2020 y 2030, en el contexto de una guerra inminente entre Nicaragua y Costa Rica por los derechos de navegación en el río San Juan ${ }^{28}$. Tal amenaza conlleva un recrudecimiento de la xenofobia en ambos países, pues el gobierno de Costa Rica decide repatriar a la totalidad de nicaragüenses que viven en su territorio.

El texto narra dos historias paralelas que al final confluyen: la aventura de Casimiro y la historia de Yahaira y su hermano David ${ }^{29}$. Con respecto a Casimiro, es un anciano ciego que vive a orillas del

26 Méndez Vides, 136.

27 Méndez Vides, 152.

28 Marcenaro, 21. Otra novela costarricense que se caracteriza por narrar acontecimientos ubicados en el futuro respecto del momento de la escritura es El problema (1899), de Máximo Soto Hall, guatemalteco que publicó varios textos en Costa Rica, pues vivió algunos años en el país. En El problema, los acontecimientos se desarrollan en 1928. Véase Máximo Soto Hall, El problema (San José. Editorial de la Universidad de Costa Rica, 1992).

29 El encuentro de los personajes sucede en Los Chiles, poblado costarricense cercano a la frontera: por diversas circunstancias, Yahaira cuida de Casimiro cuando este se encuentra agonizante y se encarga de cumplir con su última voluntad: morir en un islote del San Juan para convertir las aguas del río en vino tinto. Marcenaro, 169-175. 
Lago de Nicaragua, o Lago Cocibolca. Él solo espera la muerte acompañado por su perro $\mathrm{Buch}^{30}$, hasta que recibe un don que recuerda a los milagros de Cristo, al poder convertir el agua en vino con su sangre. Tal don sirve para poner fin a las hostilidades entre ambos países, al convertir el cauce del San Juan en vino del que, al final del relato, beben a ambas orillas del río.

Por su parte, Yahaira ingresa a Costa Rica con un propósito muy claro: encontrarse con Rico Ugalde, jugador del club de fútbol Saprissa, para casarse con él. La relación entre ambos surge con la visita del equipo a Nicaragua para jugar con el Diriangén ${ }^{31}$. Por la noche, los jugadores van a un salón de baile; Ugalde intenta seducir a Yahaira, hecho que suscita un altercado con uno de los antiguos pretendientes de ella. El hecho acaba en un enfrentamiento a puños por un asunto de orgullo en el cual se conjugan dos aspectos en apariencia distintos, pero coincidentes en la xenofobia: el resultado del partido de futbol y el éxito de los jugadores costarricenses en conquistar a las jóvenes nicaragüenses:

La policía hizo su aparición en el momento en el que los ticos eran agredidos por un grupo de buscapleitos que les cobraba la humillante derrota del equipo local (5-0) y el atrevimiento de venir a enamorar a sus chavalas, para peores, con éxito ${ }^{32}$.

El altercado es utilizado por las autoridades para provocar la xenofobia cuando la relación diplomática es tensa. Por ello, a su regreso los jugadores del Saprissa son calificados como héroes y mártires nacionales ${ }^{33}$. Ugalde acepta los cuidados de Yahaira poco

30 La relación entre Casimiro y Buch es similar a la que se puede entablar entre dos personas: el perro habla con su dueño y puede entablar un diálogo coherente con él, hecho que será utilizado al final de la novela para mitificar la historia de Casimiro en la solución del conflicto entre Costa Rica y Nicaragua.

31 Marcenaro, 29.

32 Marcenaro, 34. Este hecho, poco antes del regreso de los jugadores a Costa Rica, es tomado a burla por los nicaragüenses, en especial, por la policía ante la petición de los jugadores de protección hasta que salieran de Nicaragua. Marcenaro, 33-36.

33 El hecho de tomar el futbol como motivo para promover hostilidades entre los países recuerda a la 
antes de salir de Nicaragua y le promete casarse con ella; sin embargo, Ugalde no está realmente interesado en el matrimonio. Para encontrarse con él, Yahaira emprende el viaje de forma ilegal, aunque debe confiar en un coyote ${ }^{34}$ y deba cruzar un territorio islamizado en la frontera de los dos países ${ }^{35}$. De este modo, el objetivo para que el migrante salga de su país es el concretar una situación ideal: el viaje hacia Costa Rica se efectúa para establecer una relación duradera con un deportista adinerado y famoso, mediante el matrimonio. E1 camino hacia ese ideal se encuentra lleno de miserias y peligros: Cayetano, el coyote que guía al grupo de nicaragüenses en el que se encuentran ella y su hermano, intenta violarla en el camino; en el altercado, pierde dos dedos de la mano.

Respecto de la descripción del lugar de destino, la ciudad de San José se caracteriza, en primer lugar, por parecer una isla. Es un universo cerrado al resto del mundo, amurallado por la naturaleza: «Caminamos toda la mañana maravillados por la ciudad y las montañas que la rodean como muros naturales de un reino mágico que bien podía prescindir del exterior», en lo cual existe un punto de similitud con la ciudad de Nueva York descrita por Méndez Vides. De día, la ciudad ofrece una imagen caracterizada por el orden, la limpieza, y un ambiente casi festivo ${ }^{36}$, que se transforma en crimen, violencia y sordidez cuando cae la noche. Además de ser una ciudad violenta y sórdida por las noches, San José se caracteriza por ser el escenario

Guerra del Futbol, entre Honduras y El Salvador, en 1969. En este enfrentamiento, al igual que en la novela, el resultado de un partido se utiliza para promover la hostilidad diplomática y el eventual enfrentamiento directo. A propósito de la Guerra del Futbol, véase Pérez Brignoli, 164-170.

34 En la región centroamericana se entiende por coyote a quien se encarga, no siempre con procedimientos lícitos, de hacer posible que los migrantes indocumentados puedan alcanzar su destino, todo ello mediante una remuneración (N. de la E.).

35 Según el texto, el país de Airrecú se encuentra entre el mojón 13-A de la frontera y el Lago de Nicaragua. Está habitado por campesinos pobres, que adoptaron la religión musulmana y conformaron un nuevo país en 1995, con el apoyo de los países islámicos, quienes donaron armamento militar. Marcenaro, 41-42. Históricamente, la república de Airrecú se encontraba en la zona fronteriza entre Nicaragua y Costa Rica, constaba de unas 231 hectáreas y tal república desapareció al poco tiempo de haberse proclamado. Véase Sandoval García, «De Calero a la trocha. La nueva disputa limítrofe entre los gobiernos de Costa Rica y Nicaragua», 180.

Marcenaro, 52. 
de una guerra en las carreteras, principalmente entre dos bandos: los conductores y los peatones, representados por los taxistas, y Capa Roja, joven que ataca a los conductores que irrespetan al peatón. Entre el gremio de taxistas y Capa Roja se entabla una lucha a muerte por los derechos del peatón; Yahaira, poco después de haber llegado a San José, expresa:

Al cruzar la calle, un taxi que irrespetó la luz roja frenó a pocos centímetros de nosotros ensordeciéndonos con un pitazo interminable [...] Como si nada, el taxista intentó continuar su camino pero sorpresivamente, un tipo con capa roja cayó aparatosamente sobre la trompa del carro y empezó a zapatearla, abollándola $[\ldots]^{37}$.

Ejemplo de esta faceta inicua de la ciudad es la llamada Calle del Deleite, una vía en el Barrio Amón ${ }^{38}$. Esta calle se presenta desde la perspectiva de Erskine, un espía que llegó a Costa Rica en una misión secreta, relacionada con la repatriación de los nicaragüenses, la guerra entre ambos países y la eliminación de Airrecú. Allí están las prostitutas contratadas como empleadas del Estado, así como clubes y bares en donde se pueden hallar jóvenes «polisexuales». En uno de esos clubes, llamado El lobo estepario ${ }^{39}$, Erskine se entera de las circunstancias políticas y sociales de Costa Rica en relación con la inmigración y las problemáticas derivadas de ella, hecho que reafirma la lectura del informe remitido a él poco después de su llegada al país.

37 Marcenaro, 53. No es casual que Capa Roja muera en un linchamiento, cuando el gremio de taxistas lo atrapa. Rojas también anota que el crimen, la noche, la ciudad y lo sórdido son constantes en la literatura contemporánea.

38 Las circunstancias arrastran a Yahaira y a su hermano a este ámbito: ella acaba como bailarina en un club nocturno, mientras que David se convierte en un travesti que huye a Puerto Rico con su pareja. Marcenaro, 166.

39 La relación entre este episodio y la novela homónima de Hermann Hesse se da en varios aspectos. Valga acotar como ejemplo, además del nombre del club, el nombre de su propietario (Herman Hesse) y el nombre con el que se hace llamar Erskine una vez dentro de este (Harry Haller, al igual que el protagonista de El lobo estepario). Marcenaro, 113-130. 
Los antecedentes que han llevado a declarar una guerra son, en el plano social, convulsos y violentos: el 7 de junio de 2015, siete mil nicaragüenses tomaban por asalto varios edificios del centro de San José, hecho que culminó con la explosión de un hotel situado frente al Teatro Nacional ${ }^{40}$; en 2020, un escultor regaló a Costa Rica una imagen gigante de sor María Romero, declarada santa poco antes, que sirvió a un cura para obrar supuestos milagros: la imagen fue robada y reapareció en Nicaragua el 24 de diciembre de ese año. En 2021, un misterioso incendio borró del mapa el poblado donde estaba la imagen. A ello se suman los intereses en conflicto de Nicaragua, Costa Rica y Estados Unidos en el canal interoceánico, construido en territorio nicaragüense, los inconvenientes de la operación ORO (Operación Repatriación Ordenada), a cargo del general colombiano Francisco Morazán ${ }^{41}$, y la batalla en las calles de San José que ha librado la banda llamada Los Nicas IV, por el control del narcotráfico ${ }^{42}$. Tales circunstancias hacen que en las relaciones entre costarricenses y nicaragüenses prevalecen la tensión y el odio, que deben sufrir David y Yahaira.

Los dos hermanos se ven obligados a vivir en la mendicidad, errantes por las calles de San José: Yahaira debe renunciar a su sueño de matrimonio con Rico Ugalde, y como David tiene dotes de poeta, ambos organizan un espectáculo callejero en el cual, acaban compitiendo contra los predicadores por la atención de los transeúntes. El hecho muestra la condición del migrante nicaragüense, la xenofobia es explícita, y además, generalizada en tanto son distintas voces las que expresan el mismo sentimiento de odio:

40 Estas características coinciden con las del Gran Hotel Costa Rica, ubicado frente al Teatro Nacional, sobre la avenida segunda de la ciudad de San José.

41 Llama la atención que este militar colombiano tenga el mismo nombre que el prócer centroamericano Francisco Morazán (1792-1842), militar que defendió la idea de formar la Federación Centroamericana, en los primeros años de independencia.

42 Marcenaro, 113-130. 
Un grupo compacto se aproximó a David:

—Muy bueno, muy bueno. ¿Y de dónde es usted?

-De Nicaragua

- ¡Ah, los nicas! Dicen que en Nicaragua el que no es poeta es hijo de pueta.

[...]

- Sabe qué, mae, aquí no queremos más nicas.

- Suave, no ve que el muchacho la está pulseando.

- Yo le doy cinco tejas para que se devuelva por donde vino.

-Yo también ${ }^{43}$.

Sin embargo, Yahaira consegue empleo en dos casas de adinerados, cuyo trato para con ella está marcado por el rechazo. Primero, trabaja como empleada doméstica en la casa de Dora Shinchilla ${ }^{44}$, hija de un taxista pirata y esposa de un electricista enriquecido por su trabajo. En esta casa, ubicada en un exclusivo barrio de Escazú, Yahaira soporta malos tratos por el hecho de ser inmigrante ilegal. Algunos de los maltratos de los que Yahaira es víctima son el retraso en el pago del salario, la prohibición de salir de la casa los fines de semana y el encierro en uno de los baños de la casa: luego de una discusión entre Yahaira y su patrona por el salario adeudado, esta «[...] la encerró en el baño y se marchó a Punta Leona como todos los fines de semana de ese verano» ${ }^{45}$. Una vez fuera de su encierro, se muestra la situación del migrante frente al sistema legal del país.

Ante las leyes, el migrante se encuentra desprotegido y no cuenta con el apoyo legal, de ahí que el texto acentúe la orfandad. Una vez fuera de la casa de los Shinchilla, Yahaira se encuentra con una patrulla, que evita para escapar de otros malos tratos: denunciar la situación de la que fue víctima implicaría la detención, deportación, y posiblemente, la violación y la muerte. Por ello, el propio sistema de justicia del país aparece viciado por el crimen y la maldad, y es

43 Marcenaro, 83.

44 Este patronímico recuerda mucho al apellido Chinchilla, frecuente en Costa Rica.

45 Marcenaro, 105. 
posible considerarlo una entidad con la que no se puede contar para la administración de la justicia ${ }^{46}$.

Este aspecto también se manifiesta en las redadas organizadas por las autoridades en establecimientos públicos y en las oficinas del Estado para detener y deportar nicaragüenses. Ejemplo de ello es la redada sorpresiva efectuada en las oficinas del Ministerio de Trabajo, y de la que Yahaira escapa por azar. El hecho de la repatriación se convierte en espectáculo mediático: el proceso de expulsión de los migrantes se lleva a cabo con la enseña de "Costa Rica para los ticos ${ }^{47}$, y con tal lema se justifica no solo la violencia contra el migrante, sino también su utilización como objeto de espectáculo, en una suerte de circo que expone sus padecimientos. Sobre este hecho, la narración describe el caso de la familia Largaespada, en el que los padres son deportados, mientras que los hijos acaban abandonados a su suerte:

A él lo detuvieron en la Avenida Central el mismo día que deportaron a su esposa. Sus seis hijos los esperaron durante una semana sin saber qué hacer. El reportaje fue impactante [...]. La hija mayor, de tan solo doce años, lloraba ante las cámaras mirando a sus hermanos menores, sucios y hambrientos: no tengo qué darles de comer, ellos quieren estar con mi mama [sic] y yo no sé qué hacer ${ }^{48}$.

El segundo trabajo de Yahaira es en una residencia privada. Esta vez se trata de una familia, también adinerada, que vive en Santa Ana. En esta ocasión, el trabajo de ella consiste en cuidar a Proserpina ${ }^{49}$, una perra que adoptó la familia. Yahaira recibe un trato despectivo, que la lleva a pensar en que los perros reciben un mejor trato que los migrantes porque una vez muerta Proserpina, la familia prescinde de los servicios de la joven, sin reconocer garantía laboral alguna. En este punto se halla un aspecto similar con lo apuntado por Margarita Rojas

46 Marcenaro, 107.

47 Marcenaro, 136.

48 Marcenaro, 137.

49 Aparece aquí una relación con la mitología: Proserpina, o Perséfone, es dentro de la tradición mitológica clásica, la esposa de Hades, dios del inframundo para griegos y latinos. Hernández de la Fuente, 134-137. 
para la novela de Méndez Vides: Rojas afirma que Ramiro es asociado a la figura del perro, mientras que en la novela de Marcenaro, la dueña de Proserpina, la echa a la calle «a morir como a un perro», pues «a todo perro flaco [aludiendo a Yahaira] se le pegan las pulgas $)^{50}$.

Una imagen del migrante distinta de las anteriores se halla cuando en la narración se trata del tercer trabajo de Yahaira: atender una cafetería en San José, de la que es propietario un nicaragüense. A diferencia del migrante descrito, este es un personaje que oprime y maltrata a sus semejantes. Aunque el relato no se detiene en tratar este asunto, basta un párrafo para describir a un migrante establecido económicamente que aprovecha la posición de desventaja de sus compatriotas: Yahaira trabaja durante poco tiempo en una cafetería «grasosa y amarillenta» en la que solo trabajan nicaragüenses y cuyo dueño es también de esa nacionalidad. No obstante, la situación deja ver que la solidaridad es un sentimiento ausente entre los mismos migrantes: el dueño echa a Yahaira para darle el puesto a una sobri$\mathrm{na}^{51}$. Por las circunstancias que ella y David deben afrontar, ambos son arrastrados a la prostitución: ella se convierte en bailarina de un club nocturno, en el que se reencuentra con Cayetano, quien desea vengarse por haber perdido unos dedos de la mano cuando intentó atacarla sexualmente de camino a Costa Rica, y David acaba como travesti, antes de huir a Puerto Rico con su última pareja ${ }^{52}$.

A lo largo de la narración, Al otro lado del San Juan cuenta con algunos tópicos recurrentes dentro de la literatura. Ejemplo de ello es el tema de la migración del campo a la ciudad. Yahaira y David abandonan su lugar de origen para buscar la prosperidad y el bienestar en las ciudades de otro país, que los lleva a buscar oportunidades de surgir en un medio hostil, que no ofrece las condiciones esperadas (en el caso de ella, un matrimonio con un futbolista adinerado).

50 Marcenaro, 111.

51 Marcenaro, 134.

52 Marcenaro, 150-152 y 166. 
Otro ejemplo de los tópicos de la tradición literaria en el texto es el antiimperialismo y los intereses norteamericanos en el área centroamericana, aspecto que se encuentra en las hostilidades entre las autoridades costarricenses y el militar estadounidense Henningsen. El texto juega con los referentes históricos para ofrecer una concepción cíclica del tiempo, en tanto la historia se repite, con ligeras variantes. Por esta razón, se acude a nombres de próceres y militares del pasado. El colombiano Francisco Morazán es el encargado de llevar a cabo la repatriación de los nicaragüenses, para ello cuenta con el apoyo de Máximo Blanco, ministro de Seguridad costarricense. Los nombres de ambos no dejan de ser sumamente significativos, pues Morazán recuerda al prócer centroamericano de principios del siglo XIX, defensor de la Federación Centroamericana, mientras que el de Máximo Blanco remite al militar que apoyó el derrocamiento de Juan Rafael Mora en $1859^{53}$.

El nombre de Henningsen también remite a un personaje de la historia centroamericana de ese siglo: Charles Frederick Henningsen fue aliado de William Walker durante la época en que este intentó adueñarse del Istmo, valiéndose de las tropas mercenarias ${ }^{54}$. En la novela, las hostilidades entre los dos primeros y Henningsen son explícitas, este llega con instrucciones dictadas por las autoridades estadounidenses y respaldadas por la Asamblea Legislativa de Costa Rica, de supervisar el proceso de repatriación, hecho que reprueban Blanco y Morazán, sobre todo, este último:

Buitres es lo que son, aves rapaces que esperan la mesa servida para actuar, como en la Segunda Guerra Mundial, cuando Europa era el campo de batalla y ustedes contribuían con las armas. Cuando fueron

53 Para los referentes históricos de Máximo Blanco y Francisco Morazán, véanse Manuel Argüello Mora, «El 14 de agosto», Obras literarias e históricas (San José: Editorial Costa Rica, 2007) 2530; y Rodolfo Pastor, Historia mínima de Centroamérica (México: El Colegio de México, 2011) 207-238, respectivamente.

54 Más detalles al respecto se encuentran en: Diómedes Núñez Polanco, «Nicaragua y el filibusterismo», Cuadernos hispanoamericanos 459 (1988): 19-30. Disponible en: <www.cervantesvirtual.com/nd/ark:/59851/bmc571w7>. 
lo suficientemente astutos para llegar a Berlín mientras los aliados europeos habían abierto la brecha. Igual que en 1856, cuando lejos de contribuir a solucionar la disputa de los nicaragüenses, William Walker pretendió elegirse presidente de Centroamérica. Igual que tantas veces..., pensaba para sus adentros Morazán que no podía disimular la cólera que le infundía la presencia de los militares gringos ${ }^{55}$.

La relación tensa entre Costa Rica y Nicaragua acaba gracias a un hecho análogo a los milagros bíblicos. El fin de las hostilidades permite comparar a Casimiro con la figura de Cristo, como víctima expiatoria, cuya sangre es convertida en vino. En la mañana del 25 de diciembre, Casimiro muere desangrado en brazos de Yahaira, sobre las aguas del San Juan. Gracias a un don otorgado por la Providencia, el agua del río se convierte en vino del cual beben los militares, poco antes de iniciar la guerra. Eso sirve para evitar el enfrentamiento y elevar el sacrificio de Casimiro a categoría mítica: «Soldados de ambos ejércitos esperaron por la llegada del torrente rojo para al menos mojarse los labios. Pero un trago fue suficiente para aclarar sus mentes y darse cuenta del absurdo que se disponían a cometer ${ }^{56}$. Tal hecho es mitificado por Buch, el perro de Casimiro, que se encarga de propagar entre los de su misma especie, la historia del hombre que convirtió el San Juan en vino:

Desde entonces el aullido de los perros es diferente, pues todos repiten la historia que han escuchado a la distancia. Aquella que cuenta la aventura de un gigante ciego que impidió que los ríos se convirtieran en sangre, transformando su sangre en vino ${ }^{57}$.

55 Marcenaro, 25.

56 Marcenaro, 178.

57 Marcenaro, 179. 


\section{Conclusión}

Aunque los temas de ambas novelas son similares, tratamiento de ciertos aspectos resulta notorio, en virtud de las particularidades de cada discurso. En el caso de Al otro lado del San Juan, se cuenta con condiciones de violencia contra la población extranjera más directas y explícitas si se las compara con la situación descrita en Las murallas. Las manifestaciones de hostilidad y xenofobia llegan al punto de organizar acciones concretas: la repatriación de nicaragüenses y la violencia se combinan con el sentimiento de nacionalismo, que desemboca en una guerra inminente por defender derechos territoriales. Tal disputa acaba de forma milagrosa e inesperada, en que media la voluntad divina al concederle a Casimiro la gracia finalizar el conflicto sin necesidad de violencia después de convertir las aguas del San Juan en vino tinto. Además, es notable que la novela cuente con un aspecto poco frecuente en la tradición literaria de la región: la anticipación temporal de los acontecimientos, puesto que la narración cuenta acciones ubicadas entre 2020 y 2030.

Ambas novelas cuentan con características comunes en cuanto a la representación del lugar de destino y de la condición del migrante. En ambas los personajes salen de su lugar de origen para buscar mejores condiciones de vida; sin embargo, tales condiciones y objetivos no se concretan, pues el lugar al que arriban (Nueva York y San José) no se ofrecen tales condiciones. Incluso las ciudades en que se hallan los personajes son espacios cerrados: la primera se halla amurallada, opuesta a la Antigua, que se describe como un espacio abierto y libre. La ciudad de San José se describe como una isla separada por las montañas que la rodean ${ }^{58}$; ello implica que los personajes de ambas novelas puedan considerarse prisioneros en un lugar que prima la marginación: en el caso de Ramiro y su amigo, acaban sumidos en la indiferencia y la incomunicación entre las personas,

58 Marcenaro, 52. 
encerradas por murallas tales como la indiferencia, los rascacielos o la ceguera; en el caso de Yahaira y David, el no dar con las condiciones esperadas los arrastra a la prostitución o a desaparecer sin dejar rastro ni noticia.

De este modo, ambas obras muestran un migrante oprimido por las circunstancias en las que viven: Ramiro tiene que vivir a costa de su amigo desde el primer día en que ambos llegan a Nueva York; para ambos, el sueño americano de amasar una fortuna para volver a la Antigua acaba defraudado por la realidad: ambos terminan viviendo como si fueran un solo personaje, dependiendo uno del otro. Por su parte, Yahaira acaba viviendo en condiciones sórdidas, aunque al final de la narración, contribuye indirectamente a evitar el enfrentamiento armado entre Costa Rica y Nicaragua, al ayudarle a Casimiro a cumplir su voluntad de morir de modo que su sangre tiña el San Juan. 